\title{
The outcome of allogeneic HSCT in older AML patients is determined by disease biology and not by the donor type: An analysis of 96 allografted AML patients $\geq 50$ years from the Czech acute leukaemia clinical register (alert)
}

\author{
P. JINDRA ${ }^{1, *}$, J. MUZIK ${ }^{2}$, K. INDRAK ${ }^{3}$, P. ZAK ${ }^{4}$, F. A. SABTY ${ }^{5}$, T. KOZAK ${ }^{6}$, P. CETKOVSKY7, V. KOZA ${ }^{1}$, M. KARAS ${ }^{1}$, L. RAIDA ${ }^{3}$, T. SZOTKOWSKI ${ }^{3}$
}

${ }^{1}$ Dpt. Haematology \& Oncology, University Hospital Pilsen, Czech Republic; ${ }^{2}$ Institute of Biostatistics and Analyses, Masaryk University, Brno, Czech Republic; ${ }^{3}$ Department of Hemato-Oncology, Faculty of Medicine and Dentistry, University Palackianae Olomouc, Czech Republic; ${ }^{4}$ Department of Medicine 2-Clinical Hematology, University Hospital and Charles University, Faculty of Medicine, Hradec Kralove, Czech Republic; ${ }^{5}$ Department of Hematology and Transfusion Medicine, Faculty of Medicine, University Hospital, Comenius University, Bratislava, Slovakia; ${ }^{6}$ Department of Clinical Hematology, Charles University Hospital Kralovske Vinohrady, Prague, Czech Republic; Institute of Hematology and Blood Transfusion, Prague, Czech Republic

${ }^{*}$ Correspondence: jindra@fnplzen.cz

Received January 26, 2013/ Accepted March 1, 2013

\begin{abstract}
Older patients with AML have poor prognosis after chemotherapy and allo-SCT was historically limited to the young patients. In the multicentre retrospective study we analyzed 96 consecutive AML patients $\geq 50$ years allografted with related $(n=59)$ or unrelated $(n=37)$ donor. The 2 - year OS and DFS rates were $45 \%$ and $42 \%$ for the whole group. The corresponding figures for related patients were $48 \%$ and $42 \%$ whereas for unrelated $42 \%$ and $42 \%$, respectively (OS p $=0,721, \mathrm{DFS} p=0,896$ ). The cumulative incidences of relapse ( $28 \%$ of all patients) and NRM mortality (26\%) were low with no significant differences among related and unrelated cohorts. Multivariate analysis revealed the only major independent variables associated with an inferior OS were unfavourable cytogenetics (RR 3.36; CI 1.66-6.83; $\mathrm{p}=0.001$ ) and advanced disease status (RR 2.30; CI 1.21-4.37; $\mathrm{p}=0.011$ ). Unfavourable cytogenetics (RR 3.00; CI 1.50-5.99; $\mathrm{p}=0.002$ ) and advanced disease at SCT (RR 2.27; CI 1.22-4.22; $\mathrm{p}=0.009$ ) were also the only independent variables associated with inferior DFS. In conclusion, our analysis indicates that outcomes of allografted AML patients aged $\geq 50$ years are determined by cytogenetic risk category and disease status at transplantation and not by the type of donor.
\end{abstract}

Key words: AML, allogeneic HSCT, age, donor

Acute myeloid leukaemia is disease prevalent of elderly patients with the median age at presentation approaching 70 years [1]. In this age group the disease is almost incurable by standard treatments used for younger patients $[2,3]$. Allogeneic haematopoietic stem cell transplantation (SCT) is currently considered best curative approach for younger patients with acute myeloid leukaemia [4-6]. Because of the high toxicity the procedure was historically limited to the young patients. Advances in supportive care and the advent of reduced-intensity conditioning (RIC) regimens allowed to profit from this procedure to older age groups and promising results using related siblings were published [7]. However there has been reluctance for using matched unrelated donors (MUD) as unrelated HCT for older patients has been considered to be compromised with unacceptable high transplant relatedmortality and worse immediate availability of the donor [8]. The more sophisticated HLA typing and expanded pool of unrelated donors worldwide allowed refinements in the donor selection and recently similar outcomes using related and unrelated donors were reported [9-13]. Although genoidentical sibling is still donor of choice, few important drawbacks are obvious. Such a donor is available only in $25-30 \%$ and the siblings of elderly pts are naturally older and often ineligible for stem cell collection. Also, it is not possible to take into account donor characteristics that may impact HCT outcome such as donor age, CMV status, sex, cell dose [14-16]. On the other hand, even with high-resolution HLA typing, perfectly matched unrelated donor remains disparate for numerous 
minor histocompatibility antigens and/or antigens associated with HLA haplotype matching [17] which may contribute to the higher rates of GVHD and consequently TRM compared to related donors.

As especially older donor age has been reported to be associated with worse outcome of SCT [14] the question is whether younger age of unrelated donors could compensate for the higher immune incompatibility.

We have retrospectively investigated the outcomes of 96 consecutive patients with AML older than 50 years who underwent allogeneic SCT in the 5 Czech and Slovak centres and were reported to the Czech Acute Leukaemia Register (ALERT). The aim was (1) to evaluate the impact of donor type on survival after SCT and (2) to assess which other factors seemed to be the most significant determinants of SCT outcome in this specific patient group.

\section{Patients and methods}

Study population. The study was retrospective historical design based on the anonymized data included in the Czech Acute Leukaemia Registry (ALERT) database. Inclusion criteria were AML diagnosed according the WHO criteria, age older than 50 years at the time of SCT, allogeneic SCT performed between January 2000 and December 2007 either with HLA identical sibling or 9-10/10 HLA identical MUD. Included were all consecutive patients fulfilling inclusion criteria. Patients transplanted with haploidentical donors were excluded. Preparative regimens were classified as either RIC or standard myeloablative (MA). All patients signed local informed consent for the anonymized analyses of clinical data.

Study endpoints and definitions. Favourable, intermediate and unfavourable risk cytogenetics was assigned according to SWOG/ECOG criteria [18]. For analysis the AML status at the time of SCT was classified as either early $(\mathrm{CR} 1,2)$ or advanced (CR3, PR, primary induction failure - PIF, refractory relaps). Primary outcomes were overall survival (OS), disease-free survival (DFS, defined as survival without death or relapse), non-relapse mortality (NRM, defined as any death in continuous remission) and hematologic relapse. Secondary endpoints were incidence of acute graft-versus-host disease (GVHD) and presence or absence of chronic GVHD [19,20]

Patient characteristics. Table 1 lists all patients, diseases, and transplantation related variables for the whole group and for sibling and MUD cohorts, respectively.

The median patient age was 56 years (range, 50 to 68 years) with 73 patients (76\%) age 50 to 60 years and $23(24 \%)$ age older than 60 years. There was no difference in age between related and unrelated cohort. Majority of patients were transplanted in early disease and there was no difference in proportion of more advanced disease stage at transplantation between recipients of related donors or MUD ( $32 \%$ vs. $24 \%$, $\mathrm{p}=0.668$ ). The proportion of cytogenetic risk categories were well balanced in the different donor groups $(\mathrm{p}=0.831)$.
Donors \& HLA matching\&stem cell source. Donors were 59 HLA identical siblings and 37 unrelated HLA-A,-B,-C,-DR,DQ completely matched donors $(10 / 10, \mathrm{n}=22)$ or partially mismatched $(9 / 10, \mathrm{n}=14$ or $8 / 10, \mathrm{n}=1)$. All unrelated donor/ recipients pairs were DNA typed at the allelic level (high-resolution typing) for all loci. Peripheral blood stem cells (PBSC) were the stem cell source in all but 5 patients (5\%). Unrelated donors were significantly younger than siblings (median 32 $\mathrm{v} 55$ years, $\mathrm{p}<0.001)$. Patients in the MUD cohorts received more CD $34+$ cells (median $6.5 \times 10^{6} / \mathrm{kg}$, range $2.0-18$ vs. $4.7 \times 10^{6} / \mathrm{kg}$, range $\left.1.0-9.6, \mathrm{p}=0.004\right)$. There was no difference in the representation of CMV negative donor-recipient pairs between the MUD and sibling cohort.

Conditioning. A majority $(\mathrm{n}=60,63 \%)$ of the patients received reduced-intensity conditioning which consisted of fludarabine in various combination with melphalan or busulfan or TBI. Conventional myeloablative conditioning regimens were used in 36 patients (37\%) and the most frequent were busulfan in combination with cyclophosphamide $(75 \%)$ or TBI (10-12Gy) combined with cyclophosphamide or fludarabine (25\%). There was no difference in donor type between RIC and conventional conditioned patients.

GVHD prophylaxis \& treatment. GVHD prophylaxis was based on calcineurin inhibitors (cyclosporine or tacrolimus) in all patients. The treatment of GVHD varied among centres with standard initiation of steroids in all patients. Incidences of grades I-IV acute GVHD and chronic GVHD were determined according the established criteria [19, 20]. Chronic GVHD was evaluated in patients who survived at least 100 days with sustained engraftment.

Statistical analysis. Patient characteristics were summarized using frequency tables and standard descriptive statistics. Probabilities of overall survival (OS) and diseasefree survival (DFS) were estimated using the Kaplan-Meier method. Univariate analyses to evaluate differences in survival between groups of patients were performed using the log-rank test and Wald's test. The Cox proportional hazards model was considered for the survival modelling, multivariate survival analysis was used to specify the role of individual prognostic factors in assessing the OS and DFS. A multiple logistic regression model was used for identification of the significant prognostic factors on nonrelapse mortality and relapse. The point estimates were accompanied by $95 \%$ confidence intervals (CI). Level of statistical significance $\alpha=0.05$ was used in all analyses. All computations were performed using the SPSS software (version 12.0.2) and STATISTICA software (version 9.0).

\section{Results}

Survival. For the entire cohorts of patients, the 2-year Kaplan-Meier estimate for OS was 45\%. DFS of the whole cohort was $42 \%$. There were 49 deaths in total with 29 deaths out of 59 patients in the sibling cohort and 20 deaths out of the 37 patients in the MUD cohort $(\mathrm{p}=0.679)$. The main identifiable 
Table 1. Characteristics of the patients

\begin{tabular}{|c|c|c|c|c|c|c|c|}
\hline \multirow[b]{2}{*}{ Characteristic } & \multicolumn{2}{|c|}{$\begin{array}{l}\text { All patients } \\
\qquad N=96\end{array}$} & \multicolumn{2}{|c|}{$\begin{array}{l}\text { Matched siblings } \\
\qquad \mathrm{N}=59\end{array}$} & \multicolumn{2}{|c|}{$\begin{array}{l}\text { Matched unrelated } \\
\qquad \mathrm{N}=37\end{array}$} & \multirow[t]{2}{*}{$\mathbf{P}$} \\
\hline & No & $\%$ & No & $\%$ & No & $\%$ & \\
\hline Median age at HCT & & & & & & & 0,34 \\
\hline years & \multicolumn{2}{|c|}{56} & \multicolumn{2}{|c|}{55} & \multicolumn{2}{|c|}{57} & \\
\hline Range & $50-68$ & & $50-68$ & & $50-63$ & & \\
\hline AML cytogenetic risk & & & & & & & 0,83 \\
\hline Favorable & 5 & 5 & 4 & 7 & 1 & 3 & \\
\hline Intermediate & 69 & 72 & 42 & 71 & 27 & 73 & \\
\hline Unfavorable & 15 & 16 & 9 & 15 & 6 & 16 & \\
\hline Unknown & 7 & 7 & 4 & 7 & 3 & 8 & \\
\hline Disease status & & & & & & & 0,668 \\
\hline Early CR & 68 & 71 & 40 & 68 & 28 & 76 & \\
\hline Advanced & 28 & 29 & 19 & 32 & 9 & 24 & \\
\hline Donor age, years & & & & & & & $<0,001$ \\
\hline Median & & & & & & & \\
\hline Range & & & & & & & \\
\hline Donor/recipient sex match & & & & & & & 0,53 \\
\hline Male/male & 24 & 25 & 10 & 17 & 14 & 38 & \\
\hline Male/female & 28 & 29 & 18 & 30 & 10 & 27 & \\
\hline Female/male & 16 & 17 & 11 & 19 & 5 & 13 & \\
\hline Female/female & 28 & 29 & 20 & 34 & 8 & 22 & \\
\hline \multicolumn{8}{|l|}{ Donor/recipient CMV match } \\
\hline Negative/negative & 4 & 4 & 3 & 5 & 1 & 3 & 0,57 \\
\hline Mismatch $(-/+$ or $+/-)$ & 24 & 25 & 5 & 9 & 19 & 51 & $<0,001$ \\
\hline Positive/positive & 60 & 63 & 45 & 76 & 15 & 41 & $<0,001$ \\
\hline Unknown & 8 & 8 & 6 & 10 & 2 & 5 & 0,623 \\
\hline Graft type & & & & & & & 0,37 \\
\hline Bone marrow & 5 & 5 & 2 & 3 & 3 & 8 & \\
\hline Peripheral blood & 91 & 95 & 57 & 97 & 34 & 92 & \\
\hline Conditioning intensity & & & & & & & 0,83 \\
\hline Myeloblative & 36 & 38 & 23 & 39 & 13 & 35 & \\
\hline Reduced intensity & 60 & 62 & 36 & 61 & 24 & 65 & \\
\hline CD $34+$ cells transplanted $\times 10^{6} / \mathrm{kg}$ & & & & & & & 0,004 \\
\hline Median & & & & & & & \\
\hline range & & & & & & & \\
\hline
\end{tabular}

causes of death were transplant-related causes in $25(51 \%)$ and relapse in 24 (49\%).

Patients transplanted with sibling donor had OS and DFS rates at 2 -year of $48 \%$ and $42 \%$, respectively, whereas for patients with MUD the corresponding figures were $42 \%$ and $42 \%$. The differences in OS and DFS between sibling and MUD cohorts were insignificant (Figure 1). The strongest survival predictors in univariate analysis (see table 2 ) were intermediate/favourable $(\mathrm{RR}=0.45$; CI $0.23-0.86 ; \mathrm{P}=0.016)$ or unfavorable cytogenetics $(\mathrm{RR}=3.13$; CI 1.55-6.33; $\mathrm{P}=0.001)$ and disease status pre-SCT (patients with advanced disease $\mathrm{RR}=2.14$; CI 1.13-4.04; $\mathrm{P}=0.02$ ). Other transplant variables (donor type, conditioning, CMV status, donor gender etc) did not impact survival. The same variables were identified as significant predictors of DFS.

Nonrelapse mortality. The overall non-relapse mortality was $26 \%$ (25 patients). The incidencies of NRM were not different between the SIB and MUD cohorts (20\% versus $35 \% ; \mathrm{p}=0.245)$. Univariate analyses do not reveal any statistically significant prognostic variables associated with NRM (table 2).

Relapse or disease progression. A total of 27 patients suffered a relapse, 20 in the SIB group and 7 in MUD group. There was no significant difference in rate of disease progression or relapse between the SIB and MUD cohorts (34\% vs. $19 \% ; \mathrm{p}=0.162)$. The only significant variables influencing 

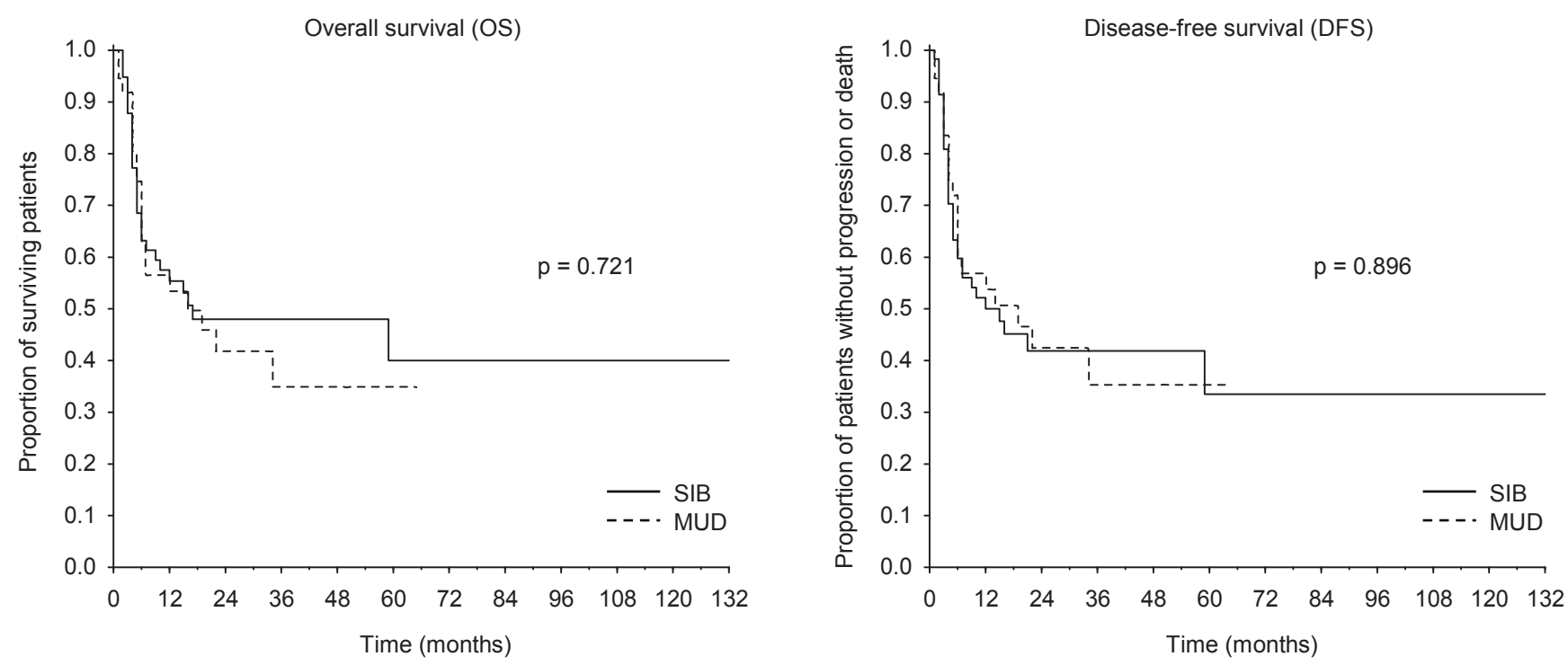

\begin{tabular}{lcccc} 
& \multicolumn{2}{c}{ OS } & \multicolumn{2}{c}{ DFS } \\
& SIB & MUD & SIB & MUD \\
& $\mathrm{N}=59$ & $\mathrm{~N}=37$ & $\mathrm{~N}=59$ & $\mathrm{~N}=37$ \\
\hline Median survival; months $(\mathrm{Cl})$ & $17.0(0.0 ; 59.1)$ & $16.0(0.0 ; 33.5)$ & $12.0(0.0 ; 25.1)$ & $19.0(1.1 ; 36.9)$ \\
Survival at 12 months; $\%(\mathrm{Cl})$ & $55.4(42.3 ; 68.5)$ & $53.3(36.5 ; 70.2)$ & $50.0(36.8 ; 63.2)$ & $53.7(36.9 ; 70.5)$ \\
Survival at 24 months; \% (Cl) & $48.0(34.2 ; 61.8)$ & $41.8(24.1 ; 59.4)$ & $41.9(27.9 ; 55.9)$ & $42.4(24.8 ; 60.0)$
\end{tabular}

Figure 1. Survival of $\geq 50$ years old allografted AML patients according to type of allogeneic HSCT $($ SIB $=$ sibling donors; MUD = matched unrelated donors).

Table 2. Univariate analysis for outcomes

\begin{tabular}{|c|c|c|c|c|c|c|c|c|c|c|c|c|}
\hline \multirow[b]{2}{*}{ Variable } & \multicolumn{3}{|c|}{ OS } & \multicolumn{3}{|c|}{ DFS } & \multicolumn{3}{|c|}{ NRM } & \multicolumn{3}{|c|}{ Relapse rate } \\
\hline & RR & $95 \% \mathrm{CI}$ & $\mathbf{P}$ & $\mathbf{R R}$ & $95 \% \mathrm{CI}$ & $\mathbf{P}$ & OR & $95 \% \mathrm{CI}$ & $\mathbf{P}$ & OR & $95 \%$ CI & $\mathbf{P}$ \\
\hline Patient age (years) & 0.99 & $(0.92-1.06)$ & 0.760 & 0.97 & $(0.90-1.04)$ & 0.330 & 1.13 & $(0.97-1.32)$ & 0.120 & 0.87 & $(0.76-0.99)$ & 0.038 \\
\hline $\begin{array}{l}\text { Intermediate/favorable risk } \\
\text { cytogenetics }\end{array}$ & 0.45 & $(0.23-0.86)$ & 0.016 & 0.44 & $(0.24-0.83)$ & 0.011 & 1.67 & $(0.45-6.13)$ & 0.442 & 0.29 & $(0.10-0.86)$ & 0.025 \\
\hline High risk cytogenetics & 3.13 & $(1.55-6.33)$ & 0.001 & 2.84 & $(1.43-5.66)$ & 0.003 & 0.93 & $(0.24-3.58)$ & 0.920 & 2.57 & $(0.76-8.72)$ & 0.129 \\
\hline $\begin{array}{l}\text { Disease status at HCT - } \\
\text { advanced disease }\end{array}$ & 2.14 & $(1.13-4.04)$ & 0.020 & 2.16 & $(1.16-4.00)$ & 0.015 & 0.49 & $(0.13-1.78)$ & 0.278 & 4.19 & $(1.41-12.44)$ & 0.010 \\
\hline Unrelated donor & 1.06 & $(0.57-1.98)$ & 0.852 & 0.90 & $(0.49-1.66)$ & 0.736 & 2.57 & $(0.71-9.27)$ & 0.150 & 0.43 & $(0.15-1.26)$ & 0.125 \\
\hline Donor age & 1.0 & $(0.97-1.02)$ & 0.820 & 1.00 & $(0.97-1.02)$ & 0.730 & 0.98 & $(0.94-1.03)$ & 0.444 & 1.01 & $(0.97-1.04)$ & 0.787 \\
\hline Type of graft-bone marrow & 0.99 & $(0.30-3.21)$ & 0.982 & 0.90 & $(0.28-2.91)$ & 0.855 & 2.00 & $(0.17-23.96)$ & 0.584 & 0.61 & $(0.06-5.80)$ & 0.670 \\
\hline Myeloablative conditioning & 1.11 & $(0.58-2.10)$ & 0.756 & 1.13 & $(0.61-2.10)$ & 0.693 & 0.31 & $(0.08-1.19)$ & 0.087 & 2.63 & $(0.96-7.20)$ & 0.060 \\
\hline $\begin{array}{l}\text { Number of CD34+ cells } \\
\text { transplanted }\end{array}$ & 0.97 & $(0.88-1.08)$ & 0.603 & 0.96 & $(0.87-1.06)$ & 0.460 & 1.15 & $(0.90-1.48)$ & 0.256 & 0.86 & $(0.71-1.05)$ & 0.140 \\
\hline
\end{tabular}

relapse in univariate analyses (table 2 ) were age of the patient (OR 0.87; CI $0.76-0.99 ; \mathrm{p}=0.038$ ), intermediate/favourable risk cytogenetics (OR 0.29; CI $0.10-0.86 ; \mathrm{p}=0.025$ ) and advanced disease status pre-SCT (OR 4.19; CI 1.41 - 12.44; $\mathrm{p}=0.010$ )

Acute and chronic GVHD. In the entire cohort, the overall incidence of acute GVHD was $44.8 \%$, whereas the incidence of grades III-IV was $14.6 \%$. The incidences comparing SIB and MUD donors were similar both for overall and for gr. III-IV
aGVHD (42.4 versus 44.6\%; $\mathrm{p}=0.674$ and 13.6 versus $16.2 \%$; $\mathrm{p}=0.771$, respectively). Among 45 SIB and 29 MUD patients who were alive at day+100 chronic GVHD was documented in $22(49 \%)$ SIB and $12(41 \%)$ MUD ( $p=0.569)$. Similar incidence between SIB and MUD cohorts was observed also for extensive cGVHD which was $27 \%$ for the whole group and $26.7 \%$ for SIB and $27.6 \%$ for MUD ( $p=0.999$ ).

Multivariate analysis. The results of multivariate analysis of 3-year outcomes are shown in Table 3. The transplantation 
Table 3. Multivariate analysis for outcomes

\begin{tabular}{lcc}
\hline Variable & RR/OR & 95 \% CI \\
\hline Overall Survival & & Overall P \\
Unfavourable cytogenetics & 3.36 & $1.66-6.83$ \\
Advanced disease stage & 2.30 & $1.21-4.37$ \\
Disease free survival & & 0.001 \\
Unfavourable cytogenetics & 3.00 & $1.50-5.99$ \\
Advanced disease stage & 2.27 & $1.22-4.22$ \\
Relapse & & 0.002 \\
Advanced disease stage & 4.61 & 0.009 \\
Myeloablative conditioning & 2.95 & $1.48-14.36$ \\
\hline
\end{tabular}

with advanced disease (OR 4.61; CI 1.48-14.36; $\mathrm{p}=0.008)$ and use of myeloablative regimen (OR 2.95; CI 1.01-8.65; $\mathrm{p}=$ 0.048 ) were associated with increased relapse rate. No significant independent variable influencing NRM was identified in multivariate analysis. The only major independent variables associated with an inferior OS were unfavourable risk cytogenetics (RR 3.36; CI 1.66-6.83; $\mathrm{p}=0.001$ ) and advanced disease status at the time of HSCT (RR 2.30; CI 1.21-4.37; $\mathrm{p}=$ 0.011). Unfavourable cytogenetics (RR 3.00; CI 1.50-5.99; $\mathrm{p}=$ 0.002 ) and advanced disease at the time of SCT (RR 2.27; CI $1.22-4.22 ; \mathrm{p}=0.009)$ were also the only independent variables associated with inferior DFS.

\section{Discussion}

In this registry based, retrospective study we present the results of data analysis of the cohort of AML patients $\geq 50$ years that received an allogeneic SCT as a part of curative intent therapy. The contribution of recipient age toward the AML patient suitability for SCT, including with MUD has been a subject of debate in recent years.

We demonstrate that SCT in AML patients above 50 years provides sustained remission survival exceeding $40 \%$ regardless of the donor type. The adjusted relative risk of OS and DFS for patients with MUDs compared with SIB was 1.06 (CI 0.57-1.98) and 0.90 (CI 0.49-1.66). Similarly, the type of donor did not significantly affect NRM and rate of relapse. Higher (yet insignificant) relative risk of NRM with MUDs was offset by the trend for lower relapse rate. Moreover, we did not observed statistically significant differences in acute and chronic GVHD incidences.

This finding supports two main conclusions. First, it confirms the feasibility of SCT in our elderly patient population. Second, patients transplanted with unrelated donors have similar outcomes with regard to OS, DFS, NRM and relapse. These conclusions related to survival are consistent with the recently published data. Undoubtedly, there is currently firm evidence to consider both type of donor equivalent at least for younger patients [10-12] even in first remission [21]. Our observation confirms and extends avail- able data for older AML patients. In analogous retrospective study of 368 AML patients with very similar characteristics (similar median age, various conditioning intensity and disease status), Schetelig at al. reported identical transplant outcomes - 40 and $35 \%$ OS/EFS at 2 years with no difference between related and unrelated donors [13]. Similarly, no impact of donor type on the outcome was observed in the multicenter study of 274 AML patients with median age of 60 years transplanted by uniform RIC SCT [22]. McClune et al. in CIBMTR study evaluated the impact of age in 545 patients above 40 years undergoing RIC SCT for AML in CR1. Comparing to our study he has found similar two year survival with only modest difference across the age groups ( $34 \%$ to $50 \%$ ) and again he has detected no influence of donor type, even in the oldest subsets. On the other hand the greater HLA disparity in the MUD cohort adversely affected 2 -year NRM, DFS, and OS [23]. Interestingly in multivariate analysis he has reported worse DFS with older donor age. As the donors were predictably significantly younger in our MUD cohort (median 32; range $20-58$ vs 55 ; range $24-68$; $\mathrm{p}<0,001$ ), one could speculate whether the younger donor age of MUD compensates for the possible negative impact of inherent higher immune incompatibility in comparison to related donors. The advanced donor age was associated with some impairment of stem cell function [24] and Mehta et al. reported the donor age above 45 years adversely influences OS and DFS and increases the risk of relapse and TRM [25] in patients transplanted after RIC. The Cox model in our study did not reveal the effect of donor age on survival, NRM and relapse (see table 2), however the heterogeneity of our group with regard to type of conditioning and graft source may limit our finding.

Historically there was legitimate reluctance to refer older patients for unrelated SCT to patients above 50 years of age due to the presumed excess of NRM linked to higher rate of GVHD. Lim et al. in retrospective EBMT study of 1333 patients older than 50 years with MDS/secondary AML reported that use of unrelated donor was independent variable associated with nonrelapse mortality [26]. Our analysis reveal only insignificant trend for higher NRM with MUD 
(OR 2.57; CI 0.71-9.27; $\mathrm{p}=0,150$ ). Again, the relatively small number of our patients in MUD cohort might confound our results.

The multivariate analysis for main transplant outcomes reveals unexpected finding the myeloablative conditioning was marginally significantly associated with risk of relapse (HR 2.95; CI 1.01-8.65; $\mathrm{p}=0.048$ ) despite the number of patients with advanced disease at SCT and cytogenetic risk distribution were similar between RIC and myeloablative group (data not shown). This is in contrast with most of other studies showing higher relapse rate using RIC regimens [2729]. The significantly higher portion of patients with unknown cytogenetics in the myeloablative cohort ( $17 \%$ vs. $2 \%$ for the RIC, $p=0,037)$ together with smaller number of patients in myeloablative cohort $(n=36)$ might contribute to the finding. Khabori et al. recently compared the outcomes of RIC and conventional conditioning in $101 \mathrm{AML} / \mathrm{MDS}$ patients and he has not found significant difference for OS, EFS, TRM and relapse between the two cohorts [30]. He reported only disease risk was significantly associated with OS, EFS and cumulative relapse (HR 3.24; CI 1.08-10.12). Similarly Lim et al. [26] and Krauter et al. [31] concluded that disease status at transplantation is the most important prognostic factor for SCT success in elderly AML patients. As shown by univariate and multivariable analysis our data supports these. The only significant predictors of survival univariate analysis proved to be cytogenetics $(\mathrm{RR}=0.45$; $\mathrm{CI} 0.23-0.86 ; \mathrm{P}=0.016$ for intermediate/favorable and $\mathrm{RR}=3.13$; CI 1.55-6.33; $\mathrm{P}=0.001$ for unfavourable cytogenetics, respectively) and disease status at SCT $(\mathrm{RR}=2.14$; CI 1.13-4.04; $\mathrm{P}=0.02$ for patients with advanced disease at SCT).

In the multivariable Cox model the only factors consistently statistically significant for OS, EFS and relapse were advanced disease stage and (as mentioned above with exception for relapse) unfavourable cytogenetics (table 3). Overall, these results are in accordance with the recent reports $[13,26,30-31]$ where the main independent factor predicting SCT outcome in similar AML population was disease risk.

Our analysis is a retrospective study and as such it has inherent important limitations. It is naturally susceptible to bias in patient selection. With regards to heterogeneity of the population, the sample size is relatively small, especially for unrelated cohort. Because of the unavailability for many patients we were not able to assess the SCT comorbidity index scoring and thus the results of our study can be influenced by differences in patient comorbidities that drive the decision to type of donor or type of conditioning.

In summary our analysis indicates that outcomes of allografted AML patients aged $\geq 50$ years are mainly determined by disease biology, i.e. cytogenetic risk category and disease status at transplantation. Age alone and absence of related donor should not be the basis for excluding AML patient from potentially curative allogeneic SCT. Rather, transplantation either from related or unrelated donors should be considered early in the disease course, primarily in patients with poor cytogenetics.

Acknowledgements: The study was supported in part by the grants MSM 6198959205, TA ČR TA01010342 and NT12454-4/2011 (8682). Supported by the project CZ.1.05/2.1.00/03.0076 from European Regional Development Fund.

\section{References}

[1] WINGO PA, TONG T, BOLDEN S. Cancer statistics. CA Cancer J Clin 1995; 45: 8-3030. http://dx.doi.org/10.3322/ canjclin.45.1.8

[2] LOWENBERG B, ZITTOUN R, KERKHOFS H, JEHN U, ABELS J et al. On the value of intensive remission-induction chemotherapy in elderly patients of $65+$ years with acute myeloid leukemia: a randomized phase III study of the European Organization of Research and Treatment of Cancer Leukemia Group. J Clin Oncol 1989; 7: 1268-1274.

[3] MENZIN J, LANG K, EARLE CC, KERNEY D, MALLICK R The outcomes and costs of acute myeloid leukemia among the elderly. Arch Intern Med. 2002; 162: 1597-1603. http://dx.doi. org/10.1001/archinte.162.14.1597

[4] FUNG HC, STEIN A, SLOVAK M, O'DONNELL MR, SNYDER DS et al A long-term follow-up report on allogeneic stem cell transplantation for patients with primary refractory acute myelogenous leukemia: impact of cytogenetic characteristics on transplantation outcome. Biol Blood Marrow Transplant 2003; 9: 766-771. http://dx.doi.org/10.1016/ j.bbmt.2003.08.004

[5] GALE RP, HOROWITZ MM, REES JK, GRAY RG, OKEN $\mathrm{MM}$ et al Chemotherapy versus transplants for acute myelogenous leukemia in second remission. Leukemia 1996; 10: 13-19.

[6] YANADA M, MATSUO K, EMI N, NAOE T Efficacy of allogeneic hematopoietic stem cell transplantation depends on cytogenetic risk for acute myeloid leukemia in first disease remission: a metaanalysis. Cancer 2005; 103: 1652-1658. http://dx.doi.org/10.1002/cncr.20945

[7] McSWEENEY PA, NIEDERWIESER D, SHIZURU JA, SANDMAIER BM, MOLINA AJ et al Hematopoietic cell transplantation in older patients with hematologic malignancies: replacing high-dose cytotoxic therapy with graft-versus-tumor effects. Blood 2001; 97: 3390-3400. http:// dx.doi.org/10.1182/blood.V97.11.3390

[8] SZYDLO R, GOLDMAN JM, KLEIN JP, GALE RP, ASH RC et al Results of allogeneic bone marrow transplants for leukemia using donors other than HLA-identical siblings. J Clin Oncol 1997; 15: 1767-1777.

[9] HEGENBART U, NIEDERWIESER D, SANDMAIER BM, MARIS BM, SHIZURU JA et al Treatment for Acute Myelogenous Leukemia by Low-Dose, Total-Body, Irradiation-Based Conditioning and Hematopoietic Cell Transplantation. J Clin Oncol 2006; 24: 444-453. http://dx.doi.org/10.1200/ LCO.2005.03.1765

[10] YAKOUB-AGHA I, MESNIL F, KUENTZ M, BOIRON JM, IFRAH N et al Allogeneic Marrow Stem-Cell Transplantation 
From Human Leukocyte Antigen-Identical Siblings Versus Human Leukocyte Antigen-Allelic-Matched Unrelated Donors (10/10) in Patients With Standard-Risk Hematologic Malignancy: A Prospective Study From the French Society of Bone Marrow Transplantation and Cell Therapy. J Clin Oncol 2006; 24: 5695-5702. http://dx.doi.org/10.1200/ LCO.2006.08.0952

[11] MOORE J, NIVISON-SMITH I, GOH K, MA D, BRADSTOCK K et al Equivalent Survival for Sibling and Unrelated Donor Allogeneic Stem Cell Transplantation for Acute Myelogenous Leukemia. Biol Blood Marrow Transplant 2007; 13: 601-607. http://dx.doi.org/10.1016/j.bbmt.2007.01.073

[12] REMBERGER M, MATTSSON J, HAUSENBERGER D, SCHAFFER M, SVAHN BM Genomic tissue typing and optimal antithymocyte globuline dose using unrelated donors results in similar survival and relapse as HLA-identical siblings in haematopoietic stem-cell transplantation for leukaemia. Eur J Haematol 2008; 80: 419-428. http://dx.doi.org/10.1111/ j.1600-0609.2008.01047.x

[13] SCHETELIG J, BORNHAUSER M, SCHMID C, HERTENSTEIN B, SCHWERDTFEGER R et al. Matched Unrelated or Matched Sibling Donors Result in Comparable Survival After Allogeneic Stem-Cell Transplantation in Elderly Patients With Acute Myeloid Leukemia: A Report From the Cooperative German Transplant Study Group J. Clin. Oncol 2008; 26: 5183-5191. http://dx.doi.org/10.1200/JCO.2007.15.5184

[14] KOLLMAN C, HOWE CWS, ANASETTI C, ANTIN JH, DAVIES SM et al Donor characteristics as risk factors in recipients after transplantation of bone marrow from unrelated donors: the effect of donor age. Blood 2001; 98: 2043-2051. http://dx.doi.org/10.1182/blood.V98.7.2043

[15] LJUNGMAN P, BRAND R, EINSELE H, FRASSONI F, NIEDERWIESER D Donor CMV serologic status and outcome of CMV-seropositive recipients after unrelated donor stem cell transplantation: an EBMT megafile analysis. Blood 2003; 102: 4255 - 4260. http://dx.doi.org/10.1182/blood2002-10-3263

[16] RINGDEN O, SCHAFFER M, LE BLANC K, PERSSON U, HAUZENBERGER D et al Which donor should be chosen for hematopoietic stem cell transplantation among unrelated HLA-A, -B, and -DRB1 genomically identical volunteers? Biol Blood Marrow Transplant 2004; 10: 128-134. http://dx.doi. org/10.1016/j.bbmt.2003.10.001

[17] PETERSDORF EW, MALKKI M, GOOLEY TA, MARTIN PJ, GUO Z. MHC haplotype matching for unrelated hematopoietic cell transplantation. PLoS Medicine 2007; 4: e8. http://dx.doi.org/10.1371/journal.pmed.0040008

[18] SLOVAK ML, KOPECKY KJ, CASSILETH PA, HARRINGTON DH, Theil KS et al. Karyotypic analysis predicts outcome of preremission and postremission theapy in adult acute myelod leukemia: a Southwest Oncology Group/Eastern cooperative Oncology Group Study. Blood 2000; 89: 4075-4083.

[19] FILIPOVICH AH, WEISDORF D, PAVLETIC S, SOCIE G, WINGARD JR et al National Institute of Health consensus development project on criteria for clinical trials in chronic graft-versus-host disease: I. Diagnosis and Staging Work- ing Group report. Biol Blood Marrow Transplant 2005; 11: 945-956. http://dx.doi.org/10.1016/j.bbmt.2005.09.004

[20] PRZEPIORKA D, WEISDORF D, MARTIN P, KLINGEMANN HG, BEATTY P et al 1994 Consensus Conference on Acute GVHD Grading. Bone Marrow Transplant 1995; 15: 825-828.

[21] GUSTA V, TALLMAN MS, WENSHENG H, LOGAN BR, COPELAN E et al Comparable survival after HLA-wll matched unrelated or matched sibling donor transplantation for acute myeloid leukemia in first remission with unfavorable cytogenetics at diagnosis. Blood 2010; 116: 1839-1848. http://dx.doi.org/10.1182/blood-2010-04$\underline{278317}$

[22] GYURKOSZA B, STORB R, STORER BE, CHAUNCEY TR, LANGE $T$ et al Nonmyeloablative allogeneic hematopoietic cell transplantation in patiens with acute myeloid leukemia. J Clin Oncol 2010; 28: 2859-2867. http://dx.doi.org/10.1200/ JCO.2009.27.1460

[23] MCCLUNE, WEISDORF DJ, PEDERSEN TL, DA SILVA RG, TALLMAN MS et al Effect of age on outcome of reducedintensity hematopoietic cell transplantation for older patiens with acute myeloid leukemia in first komplete remission or with myelodysplastic syndrome. Clin. Oncol 2010; 28: 1878 - 1887. http://dx.doi.org/10.1200/JCO.2009.25.4821

[24] KAMMINGA LM, VAN OS R, AUSEMA A, NOACH EJ, WEERSING E et al Impaired hematopoietic stem cells functioning after serial transplantation and during normal aging. Stem Cells 2005; 23: 82-92. http://dx.doi.org/10.1634/ stemcells.2004-0066

[25] MEHTA J, GORDON LI, TALLMAN MS, WINTER JN, EVENS AM et al Does younger donor age affects outcome of reduced-intensity allogeneic hematopietic stem cell transplantation for hematologic malignancies beneficially? Bone Marrow Transplant 2006; 38: 95-100. http://dx.doi. org/10.1038/sj.bmt.1705388

[26] LIM Z, BRAND R, MARTINO R, VAN BIEZEN A, FINKE J et al Allogeneic hematopoietic stem-cell transplantation for patients 50 years or older with myelodysplastic syndromes or secondary acute myeloid leukemia. J Clin Oncol 2010; 28: 405-411. http://dx.doi.org/10.1200/JCO.2009.21.8073

[27] ALYEA EP, KIM HT, HO V, CUTLER C, DEANGELO DJ et al Impact of conditioning regimen intensity on outcome of Allogeneic hematopoietic cell transplantation for advance acute myelogenous leukemia and myelodysplastic syndrome. Biol Blood Marrow Transplant 2006; 12: 1047-1055. http://dx.doi. org/10.1016/j.bbmt.2006.06.003

[28] RINGDEN O, LABOPIN M, EHNINGER G, NIEDERWIESER D, OLSSON R et al Reduced intensity conditioning compared with myeloablative conditioning using unrelated donor transplants in patients with acute myeloid leukemia J Clin Oncol 2009; 27: 4570-4577. http://dx.doi.org/10.1200/ JCO.2008.20.9692

[29] MARTINO R, IACOBELLI S, BRAND R, JANSEN T, VAN BIEZEN A et al Retrospective comparison of reduced-intensity conditioning and conventional high-dose conditioning for Allogeneic hematopoietic stem cell transplantation using HLA-identical sibling donors in myelodysplastic syndromes. 
Blood 2006; 108: 836-846. http://dx.doi.org/10.1182/blood$\underline{\text { 2005-11-4503 }}$

[30] KHABORI MA, EL-EMARY M, XU W, GUYATT G, GALAL A et al Impact of intensity of conditioning therapy in patients aged 40-60 year with AML/myelodysplastic syndrome undergoing allogeneic transplantation. Bone Marrow
Transplant 2011; 46: 516-522. http://dx.doi.org/10.1038/ bmt.2010.164

[31] KRAUTER J, WAGNER K, STADLER M, DAMMANN E, ZUCKNICK $M$ et al Prognostic factors in allo-SCT of elderly patients with AML. Bone Marrow Transplant 2011; 46: 545-551. http://dx.doi.org/10.1038/bmt.2010.145 